\title{
Sowing the Seeds of Scientific Discovery: A Celebration of David Pope, His Legacy, and Influence
}

\section{Lynne Robinson}

Editor's Note: This is excerpted from an article that first appeared on MaterialsTechnology@ TMS. Go to http://materialstechnology.tms.org/est /article.aspx?articlelD=3625 to read the full article.

Making waves in the surfboard industry is what Edison Conner fully intends to do with an advanced materials technology that he has been developing since an undergraduate at the University of Pennsylvania (Penn). An avid surfer for most of his life, Conner, like many in the sport, was frustrated with the brittleness of standard boards built around a plastic foam core. Then, while taking an introductory materials science class with David Pope, professor and undergraduate chair of Penn's Materials Science and Engineering (MSE) Department, Conner realized that his desire for a better board could actually transform into a viable business opportunity. "The more I researched, the more convinced I was that I could leverage materials technologies to make a superior product," he recalled. "The seed was planted in Dr. Pope's class."

Pope, according to Conner, was instrumental in enabling him to grow and develop his dream "to create the world's highest-performance surfboard" past the idea stage into a clearly articulated hypothesis for his senior thesis-and the basis for his current technology. Now president of Varial Surfing Technologies, Conner will be giving a talk on his surfboard solution at the David Pope Honorary Symposium on Fundamentals of Deformation and Fracture of Advanced Metals, taking place at the TMS 2011 Annual Meeting, February 27-March 3. "Dr. Pope is a remarkable man who has been a wonderful mentor to me. I am honored to be part of this celebration of his career," said Conner.
Conner's deep regard for Dr. Pope is echoed by an array of MSE scientists and engineers who will be presenting at the symposium.

"David certainly belongs to a small number of materials scientists who had a seminal and lasting impact on our understanding of mechanical behavior of various metallic materials," said Vasek Vitek, a fellow professor at Penn and long-time collaborator of Pope's. "Our collaboration was characterized by a close link between experiment and theory. David, being an excellent experimentalist, put us theorists on the realistic path. He both initiated theoretical analyses needed to explain or interpret experimental observations and developed experiments to prove or disprove theories. Such a link between experiments and theory develops rarely and

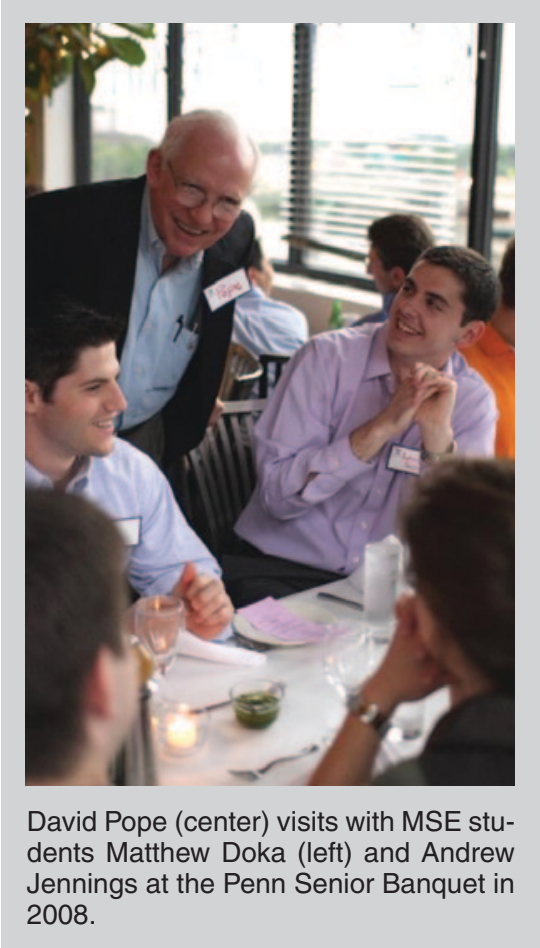

David was unique in his full understanding of the theory and ability to develop a truly relevant experimental program."

Much of Pope's greatest work, however, is not confined to the laboratory, Vitek continued: "He has also contributed immensely to the field by teaching the most introductory courses and attracting students-who really love him-to materials science. Before meeting David, many of them did not even know that this field of study and research existed."

According to Easo George, distinguished research and development staff at Oak Ridge National Laboratory (ORNL), symposium organizer, and a former graduate student of Pope's, it was how his professor presented concepts as much as what he covered that made a lasting impression. "In his classes, Dave had an uncanny ability to explain scientific concepts using everyday examples that made the material coherent and easy to understand, without sacrificing rigor, and it stayed with us permanently," he said. "A vivid recollection I have is his use of the texture of ice cream - which he described as a two-phase mixture of ice crystals and cholesterol-to bring to life Ostwald ripening in the freezer."

Admitting to being "a little embarrassed by the attention," Pope said he is nonetheless delighted at the prospect of seeing many colleagues whom he has touched-personally and scientifically - at his honorary symposium in February. "I have truly enjoyed, even cherished, my professional friends from all around the world, and am flattered that they are willing to honor me like this," he said.

Lynne Robinson is a news and feature writer for TMS. 